\title{
Peningkatan Pengetahuan Ibu Hamil terhadap Senam Hamil sebagai upaya mengurangi kejadian Ruptur Perineum
}

\author{
Khusnul Nikmah*, Eka Sarofah Ningsih, Vita Yushofa \\ Sekolah Vokasi Prodi DIII Kebidanan Universitas Islam Lamongan \\ * Correspondent Author: khusnulnikmah.80@gmail.com
}

\begin{abstract}
ABSTRAK
Senam hamil merupakan suatu bentuk latihan guna memperkuat dan mempertahankan elastisitas otototot dinding perut, ligament-ligament, otot dasar panggul yang berhubungan dengan proses persalinan. Persalinan seringkali mengakibatkan robeknya perineum atau ruptur perineum. Persalinan dengan ruptur perineum apabila tidak ditangani secara efektif menyebabkan perdarahan dan infeksi menjadi lebih berat, serta pada waktu panjang dapat mengganggu ketidaknyamanan ibu dalam berhubungan seksual. Salah satu hal untuk mencegah terjadinya ruptur perineum yaitu dengan menjaga keelastisan perineum. Peningkatan elastisitas perineum dapat dilakukan dengan senam hamil. Mengetahui Peningkatan Pengetahuan Ibu Hamil terhadap Senam Hamil sebagai Upaya Mengurangi Kejadian Ruptur Perineum di BPM Miftahul Khoiriyah Surabaya. Metode yang digunakan dalam pelaksanaan kegiatan pengabdian masyarakat ini adalah dalam bentuk ceramah atau penyuluhan dan diskusi atau tanya jawab. Dengan kita memberikan penyuluhan dan melakukan senam hamil diharapkan pengetahuan ibu hamil dapat meningkat dan akan mencegah terjadinya rupture pada persalinan, hal ini sangat penting sekali untuk disosialisasikan kepada ibu - ibu hamil yang lain supaya lebih bersemangat jika hamil lebih baik melakukan senam hamil. Maka dari itu kita sebagai tenaga kesehatan (Bidan) harus memberikan penyuluhan dan motifasi yang banyak kepada pasien untuk melakukan senam hamil selama masa kehamilan agar memperkuat dan mempertahankan elastisitas saat mengejan pada waktu bersalin.
\end{abstract}

Kata Kunci: Pengetahuan, Senam Hamil, Ruptur Perineum

Received: July 8, 2021

Revised: August 10, 2021

Accepted: September 1, 2021

This is an open-acces article distributed under the terms of the Creative Commons Attribution-ShareAlike 4.0 International License.

\section{PENDAHULUAN}

Senam hamil merupakan suatu bentuk latihan guna memperkuat dan mempertahankan elastisitas otot-otot dinding perut, ligament-ligament, otot dasar panggul yang berhubungan dengan proses persalinan.Persalinan seringkali mengakibatkan robeknya perineum atau ruptur perineum. Persalinan dengan ruptur perineum apabila tidak ditangani secara efektif menyebabkan perdarahan dan infeksi menjadi lebih berat, serta pada waktu panjang dapat mengganggu ketidaknyamanan ibu dalam berhubungan seksual (Saifuddin, 2014). Kejadian ruptur perineum pada ibu bersalin di dunia pada tahun 2015 terdapat 2,7 juta kasus, dimana angka ini diperkirakan akan mencapai 6,3 juta pada tahun 2050. Di Benua Asia sendiri $50 \%$ ibu bersalin mengalami ruptur perineum.

Salah satu hal untuk mencegah terjadinya ruptur perineum yaitu dengan menjaga keelastisan perineum. Peningkatan elastisitas perineum dapat dilakukan dengan senam hamil. Mengikuti senam hamil dapat bermanfaat dalam proses persalinan yaitu ibu dapat menjaga kondisi otot-otot dan 


\section{Journal of Community Engagement in Health}

http://jceh.org

https://doi.org/10.30994/jceh.v4i2.234

ISSN: 2620-3758 (print); 2620-3766 (online)

Vol. 4 No 2. Sep 2021. Page. 295-297

persendian yang berperan dalam proses persalinan, meningkatkan kesehatan fisik dan psikis wanita hamil serta kepercayaan pada diri sendiri dan penolong dalam menghadapi persalinan. Ruptur perineum dapat menyebabkan ketidak nyamanan dalam masa nifas yaitu memberikan rasa nyeri pada bekas jahitan dan dapat juga mengganggu mobilisasi dari ibu Post Partum, resiko infeksi juga dapat terjadi pada luka Perineum jika perawatan selama di rumah kurang tepat (Mokhtar, 2012).

Latihan senam hamil yang dirancang khusus untuk menyehatkan dan membugarkan ibu hamil, mengurangi keluhan yang timbul selama kehamilan serta mempersiapkan fisik dan psikis ibu dalam menghadapi persalinan. Senam hamil biasanya dimulai saat kehamilan memasuki trimester ketiga, yaitu sekitar usia 28 -30 minggu kehamilan tetapi tidak menuntut kemungkinan bisa dimulai sejak trimester awal. Selain untuk mencegah terjadinya robekan perineum senam hamil juga mempunyai banyak manfaat bagi ibu hamil karena Senam hamil merupakan terapi latihan gerak yang diberikan pada ibu hamil untuk mempersiapkan dirinya baik fisik maupun mental dalam menghadapi persalinan. Ibu hamil sangat membutuhkan tubuh yang sehat dan bugar. Oleh karena itu, selain makan secara teratur, ibu hamil harus cukup istirahat dan berolahraga sesuai dengan kebutuhannya. Salah satu olah raga yang baik untuk ibu hamil adalah senam hamil.(Risma, 2013).

\section{BAHAN DAN METODE}

a. Metode yang digunakan dalam pelaksanaan kegiatan pengabdian masyarakat ini adalah dalam bentuk :

1. Ceramah atau penyuluhan

2. Diskusi atau tanya jawab.

3. Memberikan contoh gerakan senam yang harus dilakukan selama hamil

b. Media

1) Leaflet Senam Hamil

2) Timbangan

3) Tensi

4) Alat Peraga Senam Hamil

- Matras

- Gym Ball

\section{HASIL DAN PEMBAHASAN}

Senam hamil adalah sebuah program berupa latihan fisik yang sangat penting bagi calon ibu untuk mempersiapkan persalinannya (Indiarti, 2008). Maka usaha yang paling sederhana untuk mencegah terjadinya rupture perineum dengan melakukan senam hamil secara teratur.

Pengabdian masyarakat ini akan dilakukan dengan cara memberikan penyuluhan dan memberikan contoh gerakan senam hamil di BPM Miftahul Khoiriyah, Amd Keb Surabaya yang bisa dilakukan dirumah. Dengan kita memberikan penyuluhan dan melakukan senam hamil diharapkan pengetahuan ibu hamil dapat meningkat dan akan mencegah terjadinya rupture pada persalinan, hal ini sangat penting sekali untuk disosialisasikan kepada ibu - ibu hamil yang lain supaya lebih bersemangat jika hamil lebih baik melakukan senam hamil. Senam hamil ini bisa dilakukan dimana saja dan kapan saja sebab tidak perlu menggunakan alat - alat yang sulit didapatkan, gerakan - gerakannya juga mudah untuk dilakukan dan waktu yang dibutuhkan juga tidak terlalu lama.

Pengabdian masyarakat yang berjudul "Peningkatan Pengetahuan Ibu Hamil Terhadap Senam Hamil Sebagai Upaya Mengurangi Kejadian Ruptur Perineum" ini merupakan satu tugas Tridarma yang harus dilakukan oleh dosen. Kegiatan dilakukan dengan kita membagikan leaflat yang ada gambar gambar senamnya dan pemeriksaan fisik sebelum kita melakukan senam sehingga ibu hamil akan lebih antusias untuk mengikuti penyuluhan yang akan kita berikan.

Melalui kegiatan pengabdian masyarakat yang kami lakukan di BPM Miftahul Khoiriyah, Amd Keb Surabaya ini diharapkan dapat meningkatkan pengetahuan ibu hamil yang melakukan pemeriksaan hamil di BPM Miftahul Khoiriyah, Amd Keb Surabaya sehingga apa yang kita berikan selama melakukan pengabdian masyarakat tentang senam hamil yang baik dan benar dapat mencegah kejadian rupture perineum pada waktu proses persalinan. Manfaat senam hamil yang dilakukan secara teratur membantu dalam menjaga kesehatan dan kelancaran proses persalinan dan nifas karena senam hamil 


\section{Journal of Community Engagement in Health}

http://jceh.org

https://doi.org/10.30994/jceh.v4i2.234

ISSN: 2620-3758 (print); 2620-3766 (online)

Vol. 4 No 2. Sep 2021. Page. 295-297

akan membuat tubuh menjadi lentur terutama pada otot-otot jalan lahir. sehingga bisa mencegah AKI (Angka Kematian Ibu) yang disebabkan karna terjadinya perdarahan yang disebabkan terjadinya rupture pada perineum. Sejalan dengan teori Oxorn, (2010) menyatakan bahwa umumnya ruptur perineum terjadi pada primipara, tetapi tidak jarang juga pada multipara. Penyebab yang biasa mengakibatkan ruptur perineum pada paritas adalah partus presipitatus, mengejan terlalu kuat, edema dan kerapuhan pada perineum, kelenturan jalan lahir, persalinan dengan tindakan. Penyebab dari faktor janin yakni berat badan lahir janin, presentasi bokong, Posisi kepala yang abnormal, Ekstraksi forcep, distosia bahu dan anomali kongenital. Maka dari itu kita sebagai tenaga kesehatan (Bidan) harus memberikan penyuluhan dan motifasi yang banyak kepada pasien untuk melakukan senam hamil selama masa kehamilan agar memperkuat dan mempertahankan elastisitas saat mengejan pada waktu bersalin.

\section{KESIMPULAN}

Senam hamil sangat penting dilakukan oleh ibu hamil yang ingin benar - benar tidak mengalami rupture perineum bila ibu hamil mau melakukan senam hamil secara rutin dan mematuhi aturan yang telah diterapkan kemungkinan pada waktu persalinan tidak akan terjadi rupture perineum.

\section{REFERENSI}

Huliana, 2001. Gizi Ibu Hamil, Penerbit Kanisius, Jakarta

Indriati, E. 2010., Antropometri Untuk Kedokteran, Keperawatan, Gizi, dan Olahraga. Yogyakarta: Citra Aji Parama

Irianto Koes. 2014. Ilmu Kesehatan Masyarakat. Bandung: Alfabet

Kemenkes RI. Profil Kesehatan Indonesia tahun 2014. Jakarta : Kemenkes RI; 2015.

Liu, D. T. Y. (2010) Manual Persalinan (Labour Ward Manual). 3rd edn. Jakarta: EGC.

Mandriwati, G.A. 2008. Penuntun Belajar Asuhan Kebidanan Ibu Hamil. Jakarta: ECG

Manuaba, I. B. G. (2015) Ilmu Kebidanan Penyakit Kandungan dan KB. Jakarta : EGC

Maryunani, A dan Sukaryati, Y. 2011. Senam Hamil, Senam Nifas, dan Terapi Musik. Jakarta: Trans Info Media

Maryunani, A. (2016) Manajemen Kebidanan Terlengkap. Jakarta Timur: TIM.

Mochtar R. 2012. Sinopsis Obstetri. Jakarta: EGC.

Rohani. 2011. Asuhan Kebidanan Pada Masa Persalinan. Jakarta : Salemba Medika.

Sindhu, Pujiastuti. (2014). Panduan Lengkap Yoga untuk Hidup Sehat dan Seimbang. Bandung: PT Mizan Pustaka

Sukarni, I. (2013) Kehamilan, Persalinan dan Nifas. Yogyakarta : Nuha Medika

Sumarah, Widyastuti, Y.\& Wiyati, N. (2009) Perawatan Ibu Bersalin (Asuhan Kebidanan pada Ibu Bersalin). Yogyakarta: Penerbit Fitramaya.

Waspodo, Djoko. 2010. Buku Acuan Pelayanan Kesehatan Maternal Dan Perinatal. Edisi pertama cetakan kelima. PT Bina Pustaka Sarwono Prawirohardjo. Jakarta. 